\title{
Dating violence victimization across the teen years: Abuse frequency, number of abusive partners, and age at first occurrence
}

Amy E Bonomi ${ }^{1,2,3^{*}}$, Melissa L Anderson ${ }^{3}$, Julianna Nemeth ${ }^{4}$, Suzanne Bartle-Haring ${ }^{1}$, Cynthia Buettner ${ }^{1}$ and Deborah Schipper ${ }^{5}$

\begin{abstract}
Background: Prior longitudinal studies have shown high cumulative dating violence exposure rates among U.S adolescents, with 36 percent of males and 44 percent to 88 percent of females experiencing victimization across adolescence/young adulthood. Despite promising information characterizing adolescents' dating violence experiences longitudinally, prior studies tended to concentrate on physical and sexual types of violence only, and did not report information on the number of times dating violence was experienced across multiple abusive partners. We used a method similar to the timeline follow-back interview to query adolescents about dating violence victimization from age 13 to 19-including dating violence types (physical, sexual, and psychological), frequency, age at first occurrence, and number of abusive partners.
\end{abstract}

Methods: A total of 730 subjects were randomly sampled from university registrar records and invited to complete an online survey, which utilized methods similar to the timeline follow-back interview, to retrospectively assess relationship histories and dating violence victimization from age 13 to 19 (eight questions adapted from widelyused surveys covering physical, sexual, and psychological abuse). Then, for each dating violence type, we asked about the number of occurrences, number of abusive partners, and age at first occurrence. Of 341 subjects who completed the survey, we included 297 (64 percent females; 36 percent males) who had a dating partner from age 13 to 19.

Results: Fully 64.7 percent of females and 61.7 percent of males reported dating violence victimization between age 13 and 19, with most experiencing multiple occurrences. More than one-third of abused females had two or more abusive partners: controlling behavior (35.6 percent); put downs/name calling (37.0); pressured sex (42.9); insults (44.3); slapped/hit (50.0); and threats (62.5). Males also had two or more abusive partners, as follows: controlling behavior (42.1 percent); insults (51.2); put downs (53.3); threats (55.6); and unwanted calls/texts/visits (60.7). Among abused females, 44.7 percent first experienced controlling behavior between age 13 and 15, whereas the majority (62.5 percent) first experienced pressured sex between age 16 and 17 . Among males, for most abuse types, 16 percent to 30 percent of victimization began before age 15 .

Conclusions: Our study adds information to a substantial, but still growing, body of literature about dating violence frequency, age of occurrence, and number of abusive partners among adolescents.

Keywords: Abuse, Violence, Sexual abuse, Adolescence, Young adults

\footnotetext{
* Correspondence: bonomi.1@osu.edu

${ }^{1}$ Human Development and Family Science, The Ohio State University,

Columbus, OH, USA

${ }^{2}$ Center for Injury Research and Policy, Nationwide Children's Hospital,

Columbus, OH, USA

Full list of author information is available at the end of the article
} 


\section{Background}

Dating violence is widespread among adolescents in the United States, with cross-sectional studies showing that between $9 \%$ and $38 \%$ of adolescents have been victimized in the past year and/or within any dating relationship [1-13]. These studies have generally shown a gender symmetry trend for psychological and physical types of dating violence among adolescents. For example, Swahn's study of adolescents recruited from a high risk, racially/ethnically diverse community showed that females and males, who reported on dating violence victimization within the last 12 months, experienced similar rates of psychological abuse (e.g., threats, insults, stalking) (38.3\% among females versus $33.7 \%$ among males) and physical abuse (e.g., slapping, hitting, scratching, pushing, kicking, punching) (28.8\% among females versus $32.6 \%$ among males) [7]. Further, studies showed that both females and males are sometimes victimized more than once by a dating partner; Coker's findings showed, for example, that $3.2 \%$ of females and $1.2 \%$ of males had been beaten by a dating partner two to three times within the last 12 months [4]. Regarding sexual violence victimization, findings from cross-sectional studies have shown that sexual violence victimization rates tend to be higher among adolescent females $(8.2 \%$ - $15.0 \%)$ compared to males $(4.9 \%$ - $7.0 \%)$ [1,7] in recent dating relationships.

Studies have also captured adolescents' longitudinal experience of physical and/or sexual violence beginning in adolescence through young adulthood [14-20]. Halpern and colleagues (2009) followed a longitudinal sample of males and females to determine physical and sexual violence victimization onset timing and persistence between adolescence and adulthood; their findings showed that $36 \%$ of males and $44 \%$ of females experienced victimization by adulthood and $7 \%$ of the total sample had persistent victimization from adolescence to adulthood [15]. Smith's (2003) study, which included women age 18 and 19 recruited during their freshmen year in college, showed that girls victimized in high school were at significantly greater risk of revictimization in college, including risk of more than one type of victimization; overall, $88 \%$ of the sample experienced physical or sexual assault from age 14 through the fourth year of college and $63.5 \%$ experienced covictimization [14]. Other longitudinal studies also showed similar trends of sexual and physical violence revictimization; once victimized in adolescence, subjects were at increased risk for revictimization in young adulthood/college years [16-20]. In addition to these studies, within the context of longitudinal intervention studies aimed at reducing dating violence, Foshee and colleagues showed that dating violence victimization could be reduced in males and females up to four years after the intervention was delivered [21]. In sum, these longitudinal studies were instrumental in adding to our understanding of how and when physical and sexual types of violence occur. However, the studies did not include psychological/emotional types of dating violence and similarly did not break down information about the number of dating violence occurrences and the number of abusive partners subjects had.

In addition to the high prevalence of dating violence among adolescents shown in U.S. studies and the tendency for re-victimization, as a public health concern, dating violence victimization has been shown to be associated with adverse mental and physical health problems, including depression, anxiety, suicide attempts, injuries, problem alcohol use and drug use, disordered eating, and risky sexual behavior [2-11,20]. Teens from racial and ethnic minority groups may be at disproportional risk for experiencing health burdens due to victimization. A study of 8,000 predominantly African American and Hispanic teens recruited from New York City high schools showed that dating violence victimization was among the top risk factors for females making a suicide attempt (61 percent more likely than non-victimized females) [5].

Despite the large body of extant literature documenting prevalence of dating violence victimization and health correlates, including longitudinal studies that have characterized adolescents' experience of dating violence at multiple points in time [14-20], prior studies have not, to date, collectively characterized across the adolescent period (ages 13 to 19) all dating violence types (physical, sexual, and psychological/emotional), the number of times adolescents experience each of these abuse types, and the number of partners who perpetrated each abuse type. In the present investigation, we used a method similar to the timeline follow-back interview to query adolescents about their experiences of dating violence from age 13 to 19-including dating violence types, frequency, age at first occurrence, and number of abusive partners. The timeline follow-back assessment method has been widely used in studies to retrospectively capture at risk behaviors, such as drug and alcohol use, among adolescents [22-24]. We adapted the method to capture both relationship and dating violence histories in a sample of college students. While retrospective dating violence assessment may result in under-reporting of abuse due to issues of recall bias [25], retrospective assessment is the field's standard for capturing dating violence experiences and our assessment method used memory prompts to facilitate recall, which we describe in more detail in the methods section.

The 2009 Institute of Medicine report - Preventing Mental, Emotional, and Behavioral Disorders Among 
Young People - called for a critical focus on the prevention of mental, emotional and behavioral disorders in young people [26]. Given that dating violence has been associated with mental and behavioral health issues that may be a result of the violence or a contributing factor to it, our study attempted to provide additional information about dating violence among adolescents spanning age 13 to 19, including the number of times they experienced the dating violence, the age they first experienced it, and number of abusive partners.

\section{Methods}

Data for the study were collected as part of a feasibility study for testing the study questionnaire. The feasibility study was to serve as a platform for a larger longitudinal study that tracked dating violence experiences and health outcomes across subjects' college/university career.

\section{Sample}

Study procedures were approved by the institutional review board of The Ohio State University (Columbus, Ohio, United States). A random sample of 730 female and male students ages 18 to 21 enrolled at The Ohio State University on January 1, 2011 were identified through the registrar's office to participate in a one-time only internet survey to assess dating violence experiences from age 13 to 19 and health. Subjects were credited $\$ 20$ to their university student account for their participation in the study. During the first week of the academic spring quarter, using students' university email account, we sent a recruitment email to all 730 students along with the study information sheet and link to the online survey. Two follow-up reminders were sent by email, three and seven days after the initial email, reminding students to complete the survey. The overall response rate at each recruitment email was as follows: initial email (31.6\%, 231/730); second email (41.0\%, 300/ $730)$; final email $(46.7 \%, 341 / 730)$ - rates similar to prior studies of adolescents recruited using random sampling $[27,28]$. The response rate for the study was relatively low (46.7\%), and we did not have information on non-respondents to assess potential response bias. However, our study respondents were remarkably similar to the Ohio State student population in general on critical socio-demographic factors, including age, race/ethnicity (17\% comprised racial/ethnic minorities, consistent with the Ohio State population), and year in school (most comprised freshmen, sophomores and juniors).

Of the 341 subjects who completed the online questionnaire, 44 were excluded because they were older than age $21(n=7)$ or because they reported never having a dating, romantic or sexual partner between age 13 and $19(\mathrm{n}=37)$. After these exclusions, the final analytic sample comprised 271 subjects $(n=190$ females; $n=107$ males).

\section{Survey}

We used a method similar to the timeline follow-back interview to retrospectively assess subjects' dating violence victimization histories from age 13 to 19 [22-24]; we had previously used this timeline follow-back interview method to document domestic violence and child abuse histories in more than 4,000 women and men [2938]. As noted, while retrospective dating violence assessment may result in under-reporting of abuse due to issues of recall bias [25], retrospective assessment is the field's standard for capturing dating violence experiences and our assessment method used memory prompts to facilitate recall. Namely, first, to establish relationship histories [29-38], subjects were asked whether they had a dating, romantic or sexual partner between age 13 and 19. They were then asked specific details about their three most recent partners, starting with their most recent partner, that is, the partner they were last involved with between age 13 and 19. For each of their three most recent partners, we asked about the gender of the partner, the age that the relationship began and ended, and the type of partnership (boyfriend/girlfriend; someone the subject liked romantically and went to specific events with, such as school dances or hung out with at the movies or mall; or someone the subject "hooked up with" or had a sexual relationship, but would not consider as a boyfriend or girlfriend) [39]. Similar to the timeline follow-back interview method, we used memory prompts, such as asking the subject to remember the year they were in high school to facilitate recall of the age that a relationship began and ended. For operational practicality, this relationship information was obtained for subjects' three most recent partners, starting with their most recent partner and working back to include their two partners before that. Our decision to stop at asking detailed questions about subjects' three most recent partnerships came from our extensive experience interviewing more than 4,000 adults, where subjects consistently expressed a desire to stop being asked beyond their third most recent relationship [29-38]. Of note, $63.4 \%$ (282 of 445 ) of females in our current adolescent sample and 70\% (98 of 140) of males reported having three or fewer relationships from age 13 to 19 . After we asked subjects these detailed questions about their three most recent partners, we asked about the total number of partners subjects had beyond the three most recent partnerships from age 13 to 19 .

After information about subjects' relationship history was gathered, dating violence victimization was assessed retrospectively using eight modified questions covering the three core conceptual areas of teen dating violence 
as recognized by the Centers for Disease Control and Prevention (physical, sexual, and psychological). Table 1 includes the questions as they were administered in our survey.

Our eight questions were adapted from the Centers for Disease Control and Prevention's Youth Risk Behavior Survey Surveillance System [40], Foshee and Swahn's studies $[1,7,13]$, and Coker's teen dating violence survey currently being administered in a CDC-funded intervention study. As we were attempting to collect detailed information about subjects' relationship histories, and dating violence frequency, number of abusive partners, and age at first occurrence spanning age 13 to 19, we used this collapsed set of eight questions, rather than a larger set of dating violence questions, such as those used in studies by Foshee and Swahn $[1,7,13]$. However, as noted, our collapsed questions covered the major conceptual areas of physical, sexual, and psychological types of dating violence typically measured in other questionnaires, and as reflected in the Centers for Disease Control's conceptualization and the Teen Power and Control Wheel (a conceptual tool reflecting types of violence teens may experience in dating relationships). In a separate paper, we reported the results of a confirmatory factor analysis done on the eight dating violence questions included in our study, which predicted that the two sexual violence questions would load onto one factor, the four psychological abuse questions would load onto one factor, and finally that the two physical violence questions (including threats of physical

\section{Table 1 Dating Violence Questions}

Has any partner you've been involved with between ages 13 and 19 ever...

Physical

...hit, slap, or physically hurt you on purpose?

...threatened to hit or slap you, to spread rumors about you, to destroy something belonging to you, or to harm you in some other way?

\section{Sexual}

... pressured you to participate in sexual activities by begging or arguing with you, or by threatening to end your relationship?

... pressured you to participate in sexual activities by threatening you with physical force (i.e. twisting your arm or holding you down)?

\section{Psychological}

... tried to control your behavior by always checking up on you, telling you who your friends could be, or telling you what you could do and when?

... called you names, put down your looks, or said things to hurt your feelings on purpose?

... shouted, yelled, insulted, or sworn at you?

... made unwanted phone calls, send unwanted text messages, emails, or gifts, or showed up in person and waited for you when you didn't want them to? violence) would load onto a single factor (Nemeth et al., under review). That analysis showed that all of the factor loadings were significant in the hypothesized direction, suggesting that the variables loaded onto the proper latent variables (sexual, psychological, and physical dating violence types).

For each question in Table 1, subjects were asked whether they ever experienced dating violence between age 13 and 19. For subjects who indicated they experienced any given dating violence type, they were then asked if 1) they experienced the violence in their last three relationships (reported on earlier in the survey) and any additional relationships beyond their most recent three; 2) the number of times they experienced each violence type; and 3) the age at first occurrence. For the two questions that addressed sexual violence, we asked about whether alcohol consumption was involved (partner, self, both, neither). For each dating violence type, subjects who responded with "yes" were considered exposed to that dating violence type.

\section{Data analysis}

In gender-stratified analyses, we estimated overall dating violence prevalence (exposure was defined as a response of "yes" to any of the eight dating violence questions in Table 1), and then prevalence of each of the eight dating violence types (response of "yes" to each respective dating violence type signified exposure to that dating violence type). Confidence intervals and relative standard errors (RSE) were computed for the prevalence estimates. Prevalence estimates with RSE over $30 \%$ may be unreliable. Estimates with RSE $>30 \%$ are marked with an asterisk later in the results section and should be used with caution. Among subjects reporting dating violence, we then summarized the number of times the dating violence occurred, the number of partners the dating violence occurred with, and the age at first occurrence.

\section{Results}

\section{Subject characteristics}

Table 2 shows the characteristics of subjects. Consistent with The Ohio State University student population in general, the sample comprised mostly White subjects (83\%). Most subjects reported heterosexual orientation ( $89.0 \%$ of females and $87.9 \%$ of males), and most were freshmen, sophomores or juniors from age 19 to 21 .

\section{Prevalence of dating violence}

Table 3 depicts prevalence results. A total of $64.7 \%$ of females and $61.7 \%$ of males reported experiencing any type of dating violence from age 13 to 19 .

Among females, psychological dating violence rates were: $24.7 \%$ (controlling behavior); 27.4\% (unwanted 
Table 2 Subject Characteristics

\begin{tabular}{|c|c|c|}
\hline & Females $(\mathrm{N}=190)$ & Males $(\mathrm{N}=107)$ \\
\hline Age & $N(\%)$ & $N(\%)$ \\
\hline 18 & $28(14.7)$ & $15(14.0)$ \\
\hline 19 & $58(30.5)$ & $39(36.5)$ \\
\hline 20 & $62(32.6)$ & $25(23.4)$ \\
\hline 21 & $42(22.1)$ & $28(26.2)$ \\
\hline \multicolumn{3}{|l|}{ Year in college } \\
\hline Freshman & 60 (31.9) & $41(38.3)$ \\
\hline Sophomore & 65 (34.6) & $32(29.9)$ \\
\hline Junior & $49(26.1)$ & $24(22.4)$ \\
\hline Senior & $14(7.5)$ & $10(9.4)$ \\
\hline missing & 2 & 0 \\
\hline \multicolumn{3}{|l|}{ GPA } \\
\hline 2.6 or lower & $13(6.8)$ & $5(4.7)$ \\
\hline 2.7 to 2.9 & $24(12.6)$ & $18(17.0)$ \\
\hline 3.0 to 3.6 & $110(57.9)$ & $59(55.7)$ \\
\hline 3.7 to 4.0 & $43(22.6)$ & $24(22.6)$ \\
\hline missing & 0 & 1 \\
\hline \multicolumn{3}{|l|}{ Race } \\
\hline White & $156(82.8)$ & 89 (83.2) \\
\hline Black & $12(6.4)$ & $7(6.5)$ \\
\hline Asian & $16(8.5)$ & $10(9.4)$ \\
\hline Other & $5(2.7)$ & $1(0.9)$ \\
\hline missing & 1 & 0 \\
\hline \multicolumn{3}{|l|}{ Sexual orientation } \\
\hline Heterosexual & $169(89.0)$ & $94(87.9)$ \\
\hline Bisexual & $10(5.3)$ & $1(0.9)$ \\
\hline Homosexual & $4(2.1)$ & $7(6.5)$ \\
\hline Asexual & $7(3.7)$ & $5(4.7)$ \\
\hline
\end{tabular}

† Missing responses not included in denominator when calculating percentages.

$\mathrm{GPA}=$ grade point average.

calls/texts/visits); $30.5 \%$ (name calling/put downs); and $42.6 \%$ (insults/yelling/swearing). Nearly $25 \%$ of females experienced sexual pressure due to a partner's persistent begging or threats and 5\% due to physical force, 9\% experienced threats of physical force, and 3.7\% had been hit, slapped or otherwise physically hurt by a partner.

Among males, psychological dating violence rates were: $15.0 \%$ (put downs/name calling); 18.7\% (controlling behavior); $27.1 \%$ (unwanted calls/texts/visits); and $43.9 \%$ (insults/yelling/swearing). A total of $11 \%$ of males experienced sexual pressure due to partner's persistent begging or threats, and 1\% due to physical force, $9.3 \%$ experienced threats of physical force and $13.1 \%$ had been hit, slapped or otherwise physically hurt by a partner.
Table 3 Prevalence of Dating Violence

\begin{tabular}{|c|c|c|c|c|}
\hline $\begin{array}{l}\text { Female respondents } \\
(\mathrm{N}=190)\end{array}$ & $\begin{array}{l}\text { \# reporting } \\
\text { abuse }\end{array}$ & Prevalence & $95 \% \mathrm{Cl}$ & RSE \\
\hline Any abuse & 123 & 64.7 & $57.9,71.6$ & 5 \\
\hline \multicolumn{5}{|l|}{ Specific abuse types } \\
\hline Controlling behavior & 47 & 24.7 & $18.5,30.9$ & $\begin{array}{l}9 \\
9\end{array}$ \\
\hline Put downs, name calling & 58 & 30.5 & $23.9,37.1$ & 11 \\
\hline Insults, yelling, swearing & 81 & 42.6 & $35.5,49.7$ & 8 \\
\hline Unwanted calls, texts, visits & 52 & 27.4 & $21.0,33.8$ & 312 \\
\hline Threats & 17 & 9.0 & $4.9,13.1$ & 23 \\
\hline Hit, slap, physically hurt & 7 & $3.7^{*}$ & $1.0,6.4$ & 37 \\
\hline Pressured into sex, begging & 45 & 23.8 & $17.7,29.9$ & $9 \quad 13$ \\
\hline $\begin{array}{l}\text { Pressured into sex, threat } \\
\text { of physical force }\end{array}$ & 9 & $4.8^{*}$ & $1.7,7.8$ & 33 \\
\hline $\begin{array}{l}\text { Male respondents } \\
(\mathrm{N}=107)\end{array}$ & $\begin{array}{l}\text { \# reporting } \\
\text { abuse }\end{array}$ & Prevalence & $95 \% \mathrm{Cl}$ & RSE \\
\hline Any abuse & 66 & 61.7 & $52.3,71.0$ & 8 \\
\hline \multicolumn{5}{|l|}{ Specific abuse types } \\
\hline Controlling behavior & 20 & 18.7 & $11.2,26.2$ & 20 \\
\hline Put downs, name calling & 16 & 15.0 & $8.1,21.8$ & 23 \\
\hline Insults, yelling, swearing & 47 & 43.9 & $34.4,53.5$ & 11 \\
\hline Unwanted calls, texts, visits & 29 & 27.1 & $18.5,35.7$ & 16 \\
\hline Threats & 10 & $9.3^{*}$ & $3.7,15.0$ & 30 \\
\hline Hit, slap, physically hurt & 14 & 13.1 & $6.6,19.6$ & 25 \\
\hline Pressured into sex, begging & 12 & 11.2 & $5.1,17.3$ & 27 \\
\hline $\begin{array}{l}\text { Pressured into sex, threat } \\
\text { of physical force }\end{array}$ & 1 & $1.0^{*}$ & $0.0,2.8$ & 100 \\
\hline
\end{tabular}

$C l=$ Confidence Interval; $R S E=$ relative standard error.

*This estimate should be used with caution. Estimates with RSE > 30\% may be unreliable.

Number of abusive partners, number of dating violence occurrences, and Age at first occurrence

Tables 4 and 5 presents information on number of abusive partners, number of dating violence occurrences, and age at first occurrence.

\section{Number of abusive partners}

In contrast to our studies on adults where most women and men indicated they had only one abusive partner $[29,38]$, teens tended to report that more than one partner perpetrated dating violence toward them. Among females who reported dating violence, more than onethird indicated that they had experienced the dating violence from two or more partners, as follows: controlling behavior (35.6\%); put downs/name calling (37.0\%); pressured sex (42.9\%); insults (44.3\%); slapped/hit (50.0\%); and threats $(62.5 \%)$. A sizable proportion of males who experienced dating violence also said they had two or more partners who perpetrated the violence, as follows: controlling behavior (42.1\%); insults (51.2\%); put downs 
Table 4 Dating Violence Chronicity (Female respondents)

\begin{tabular}{|c|c|c|c|c|c|c|c|c|}
\hline $\begin{array}{l}\text { Female respondents } \\
(\mathrm{N}=190)\end{array}$ & $\begin{array}{l}\text { Controlling } \\
\text { behavior }\end{array}$ & $\begin{array}{l}\text { Put downs, } \\
\text { name calling }\end{array}$ & $\begin{array}{l}\text { Yell, swore, } \\
\text { insulted }\end{array}$ & $\begin{array}{l}\text { Unwanted } \\
\text { calls, texts, visits }\end{array}$ & Threaten & $\begin{array}{l}\text { Hit, } \\
\text { slapped, hurt }\end{array}$ & $\begin{array}{l}\text { Pressured into } \\
\text { sex, begging }\end{array}$ & $\begin{array}{l}\text { Pressured into } \\
\text { sex, threat }\end{array}$ \\
\hline \multirow[t]{2}{*}{ Number reporting abuse } & $\mathrm{N}=47$ & $N=58$ & $N=81$ & $N=52$ & $\mathrm{~N}=17$ & $\mathrm{~N}=7$ & $N=45$ & $N=9$ \\
\hline & $\mathrm{n}(\%) \dagger$ & $\mathrm{n}(\%)+$ & $\mathrm{n}(\%) \dagger$ & $\mathrm{n}(\%) \dagger$ & $\mathrm{n}(\%) \dagger$ & $\mathrm{n}(\%)+$ & $\mathrm{n}(\%) \dagger$ & $\mathrm{n}(\%)+$ \\
\hline \multicolumn{9}{|c|}{ Number of abusive partners } \\
\hline 1 & $29(64.4)$ & $34(63.0)$ & $44(55.7)$ & $32(64.0)$ & $6(37.5)$ & $3(50.0)$ & $24(57.1)$ & $5(62.5)$ \\
\hline 2 & $13(28.9)$ & $15(27.8)$ & $25(31.7)$ & $12(24.0)$ & $6(37.5)$ & $3(50.0)$ & $11(26.2)$ & $2(25.0)$ \\
\hline $3+$ & $3(6.7)$ & $5(9.3)$ & $10(12.7)$ & $6(12.0)$ & $4(25.0)$ & $0(0.0)$ & $7(16.7)$ & $1(12.5)$ \\
\hline missing & 2 & 4 & 2 & 2 & 1 & 1 & 3 & 1 \\
\hline \multicolumn{9}{|l|}{ Number of occurrences } \\
\hline 1 & $8(17.0)$ & $13(23.2)$ & $14(17.3)$ & $9(18.0)$ & $6(35.3)$ & $4(66.7)$ & $8(18.2)$ & $4(50.0)$ \\
\hline $2-5$ & $12(25.5)$ & $19(33.9)$ & $34(42.0)$ & $21(42.0)$ & $5(29.4)$ & $1(16.7)$ & $18(40.9)$ & $1(12.5)$ \\
\hline $6-11$ & $7(14.9)$ & $8(14.3)$ & $5(6.2)$ & $4(8.0)$ & $0(0.0)$ & $0(0.0)$ & $5(11.4)$ & $1(12.5)$ \\
\hline $11-20$ & $4(8.5)$ & $2(3.6)$ & $11(13.6)$ & $4(8.0)$ & $2(11.8)$ & $0(0.0)$ & $6(13.6)$ & $0(0.0)$ \\
\hline$>20$ & $6(12.8)$ & $4(7.1)$ & $7(8.6)$ & $8(16.0)$ & $3(17.7)$ & $1(16.7)$ & $5(11.4)$ & $2(25.0)$ \\
\hline don't remember & $10(21.3)$ & $10(17.9)$ & $10(12.4)$ & $4(8.0)$ & $1(5.9)$ & $0(0.0)$ & $2(4.6)$ & $0(0.0)$ \\
\hline missing & 0 & 2 & 0 & 2 & 0 & 1 & 1 & 1 \\
\hline \multicolumn{9}{|l|}{ Age at first occurrence } \\
\hline $13-15$ & $21(44.7)$ & $20(35.1)$ & $22(27.2)$ & 15 (28.9) & $5(29.4)$ & $0(0.0)$ & 17 (38.6) & $2(25.0)$ \\
\hline $16-17$ & $20(42.6)$ & $24(42.1)$ & $39(48.2)$ & 19 (36.5) & $5(29.4)$ & $4(66.7)$ & 17 (38.6) & $5(62.5)$ \\
\hline $18-19$ & $6(12.8)$ & $13(22.8)$ & $20(24.7)$ & 18 (34.6) & $7(41.2)$ & $2(33.3)$ & $10(22.7)$ & $1(12.5)$ \\
\hline missing & 0 & 1 & 0 & 0 & 0 & 1 & 1 & 1 \\
\hline \multicolumn{9}{|l|}{ Was alcohol involved } \\
\hline No & & & & & & & $31(70.5)$ & $5(62.5)$ \\
\hline Yes & & & & & & & 13 (29.6) & $3(37.5)$ \\
\hline missing & & & & & & & 1 & 1 \\
\hline
\end{tabular}

† Missing responses not included in denominator when calculating percentages.

(53.3\%); threats (55.6\%); and unwanted calls/text messages $(60.7 \%)$

\section{Number of dating violence occurrences}

Among female and males reporting violence, dating violence was rarely reported as an isolated incident. Dating violence was commonly experienced as 2 to 5 occurrences of each dating violence type. However, of note, roughly $15 \%$ of females and males reported 20 or more occurrences of some dating violence types. Namely, for females, $16.0 \%$ experienced 20 or more occurrences of unwanted calls/texts/visits, $17.7 \%$ experienced threats, $16.7 \%$ were hit, and $25.0 \%$ were pressured sexually using physical force. For males, $15.0 \%$ experienced 20 or more occurrences of controlling behavior and $14.3 \%$ experienced unwanted calls/texts/visits.

\section{Age at first occurrence from age 13 to 19}

Some dating violence types tended to occur at earlier ages than other dating violence types. For example, among females reporting dating violence, $44.7 \%$ reported that they first experienced controlling behavior between the ages of 13 and 15, whereas the majority of females (62.5\%) reporting being pressured into sex due to threats or physical force first experienced this type of dating violence between the ages of 16-17. Among males, age 13 to 15 was the most common age at earliest occurrence of put downs/name calling (60.0\%). For most other dating violence types, between $16 \%$ and $30 \%$ of victimization began before age 15 .

\section{Discussion}

Our study used an assessment approach similar to the timeline-follow back method [22-24] to estimate dating violence victimization across the teen years (age 13 to 19), including dating violence types (physical, sexual, and psychological/emotional), frequency, age at first occurrence, and number of abusive partners. Our retrospective query approach included memory prompts, such asking subjects to remember what year they were 
Table 5 Dating Violence Chronicity (Male respondents)

\begin{tabular}{|c|c|c|c|c|c|c|c|c|}
\hline $\begin{array}{l}\text { Male respondents } \\
(\mathrm{N}=107)\end{array}$ & $\begin{array}{l}\text { Controlling } \\
\text { behavior }\end{array}$ & $\begin{array}{l}\text { Put downs, } \\
\text { name calling }\end{array}$ & $\begin{array}{l}\text { Yell, swore, } \\
\text { insulted }\end{array}$ & $\begin{array}{l}\text { Unwanted } \\
\text { calls, texts, visits }\end{array}$ & Threaten & $\begin{array}{l}\text { Hit, slapped, } \\
\text { hurt }\end{array}$ & $\begin{array}{l}\text { Pressured into } \\
\text { sex, begging }\end{array}$ & $\begin{array}{l}\text { Pressured into } \\
\text { sex, threat }\end{array}$ \\
\hline \multirow[t]{2}{*}{ Number reporting abuse } & $N=20$ & $N=16$ & $N=47$ & $N=29$ & $\mathrm{~N}=10$ & $N=14$ & $\mathrm{~N}=12$ & $\mathrm{~N}=1$ \\
\hline & $\mathrm{n}(\%) \dagger$ & n (\%)† & n (\%)† & $\mathrm{n}(\%) \dagger$ & $\mathrm{n}(\%) \dagger$ & n (\%)† & n (\%)† & $n(\%) \dagger$ \\
\hline \multicolumn{9}{|l|}{ Number of abusive partners } \\
\hline 1 & $11(57.9)$ & $7(46.7)$ & $21(48.8)$ & $11(39.3)$ & $4(44.4)$ & $8(72.7)$ & $6(54.6)$ & $1(100.0)$ \\
\hline 2 & $5(26.3)$ & $7(46.7)$ & $19(44.2)$ & $15(53.6)$ & $5(55.6)$ & $2(18.2)$ & $4(36.4)$ & $0(0.0)$ \\
\hline $3+$ & $3(15.8)$ & $1(6.7)$ & $3(7.0)$ & $2(7.1)$ & $0(0.0)$ & $1(9.1)$ & $1(9.1)$ & $0(0.0)$ \\
\hline missing & 1 & 1 & 4 & 1 & 1 & 3 & 1 & 0 \\
\hline \multicolumn{9}{|l|}{ Number of occurrences } \\
\hline 1 & $4(20.0)$ & $0(0.0)$ & $8(17.4)$ & $5(17.9)$ & $0(0.0)$ & $4(33.3)$ & $6(50.0)$ & $1(100.0)$ \\
\hline $2-5$ & $8(40.0)$ & $4(26.7)$ & $21(45.7)$ & $9(32.1)$ & $8(88.9)$ & $8(66.7)$ & $4(33.3)$ & $0(0.0)$ \\
\hline $6-11$ & $2(10.0)$ & $6(40.0)$ & $4(8.7)$ & $2(7.1)$ & $0(0.0)$ & $0(0.0)$ & $1(8.3)$ & $0(0.0)$ \\
\hline $11-20$ & $1(5.0)$ & $2(13.3)$ & $4(8.7)$ & $5(17.9)$ & $1(11.1)$ & $0(0.0)$ & $0(0.0)$ & $0(0.0)$ \\
\hline$>20$ & $3(15.0)$ & $2(13.3)$ & $4(8.7)$ & $4(14.3)$ & $0(0.0)$ & $0(0.0)$ & $0(0.0)$ & $0(0.0)$ \\
\hline don't remember & $2(10.0)$ & $1(6.7)$ & $5(10.9)$ & $3(10.7)$ & $0(0.0)$ & $0(0.0)$ & $1(8.3)$ & $0(0.0)$ \\
\hline missing & 0 & 1 & 1 & 1 & 1 & 2 & 0 & 0 \\
\hline \multicolumn{9}{|l|}{ Age at first occurrence } \\
\hline $13-15$ & $6(30.0)$ & $9(60.0)$ & $13(28.9)$ & $8(28.6)$ & $2(22.2)$ & $2(18.2)$ & $2(16.7)$ & $0(0.0)$ \\
\hline $16-17$ & $7(35.0)$ & $5(33.3)$ & $23(51.1)$ & $10(35.7)$ & $3(33.3)$ & $5(45.5)$ & $5(41.7)$ & $0(0.0)$ \\
\hline $18-19$ & $7(35.0)$ & $1(6.7)$ & $9(20.0)$ & $10(35.7)$ & $4(44.4)$ & $4(36.4)$ & $5(41.7)$ & $1(100.0)$ \\
\hline missing & 0 & 1 & 2 & 1 & 1 & 3 & 0 & 0 \\
\hline \multicolumn{9}{|l|}{ Was alcohol involved } \\
\hline No & & & & & & & $8(66.7)$ & $0(0.0)$ \\
\hline Yes & & & & & & & $4(33.3)$ & $1(100.0)$ \\
\hline missing & & & & & & & 0 & 0 \\
\hline
\end{tabular}

† Missing responses not included in denominator when calculating percentages.

in high school when they began and ended a relationship, to facilitate recall of relationship start and stop times and dating violence exposure. Our dating violence questions were adapted from prior surveys conducted by the Centers for Disease Control and Prevention (Youth Risk Behavior Surveillance System) [40], Foshee and Swahn $[1,7,13]$, and Coker's teen dating violence survey currently being administered in a CDC-funded intervention study. Across age 13 to 19 , in our sample, $64.7 \%$ of females and $61.7 \%$ of males experienced dating violence victimization; our prevalence rates fall within the range of prior longitudinal studies showing cumulative physical/sexual dating violence victimization exposure during adolescence/early adulthood of $36 \%$ for males and $44 \%$ to $88 \%$ for females $[14,15]$. Differences in the way dating violence was measured in our study (retrospective assessment of physical, sexual, and psychological/emotional violence) versus in prior longitudinal studies (assessment of physical and sexual violence) could account for prevalence rate differences.
Our study was not powered to statistically compare prevalence rates between males and females. This said, our study generally showed that females and males tended to experience comparable rates of threats (9\%), unwanted calls/texts/visits (27\%), and being yelled/sworn at (43\%), but females experienced higher rates of being put down and called names (30.5\% versus $15.0 \%)$ and sexual pressure due to persistent begging or threats (23.8\% versus $11.2 \%$ ). Our findings corroborate results from prior studies showing higher rates of sexual violence victimization in females compared to males and similar rates of psychological abuse among adolescent females and males in dating relationships $[1,4,7,15]$. In contrast to some prior studies that have shown a general gender symmetry trend for physical dating violence victimization among adolescents[7], our study showed a higher rate of physical violence among males (13.1\%) compared to females (3.7\%). While these gender differences were observed in our study, we caution readers about over-interpreting for two reasons: 1) we did not 
undertake a formal statistical comparison due to our small sample size; and 2) we did not have qualitative information about the nature of the physical violence-it is possible, for example, that in our predominantly heterosexual sample males experienced "open hand slapping" by their female partners, where females experienced more aggressive physical abuse by male partners. Lending support to this idea, prior studies have shown that males are more likely than females to report physically injuring a date [7].

Our findings on the age at first dating violence occurrence, number of occurrences, and number of abusive partners add to our understanding of how dating violence unfolds during the teen years. Females and males rarely reported an isolated incident of dating violence. While teens most commonly experienced 2 to 5 occurrences of dating violence, of note, roughly $15 \%$ of both females and males reported 20+ occurrences of some dating violence types (for females: unwanted calls/texts/ visits, threats, being hit, pressured sexually using physical force; for males: controlling behavior, unwanted calls/texts/visits). The age at first occurrence tended to be similar for males and females, with a few exceptions. Females tended to report controlling behavior earlier than males, and males tended to report put down and name calling earlier than females. In general, the first occurrence of pressure to have sex, and threats and physical harm tended to occur later than first occurrences of psychological dating violence such as controlling behavior, or name calling.

Our study results must be considered within the context of its limitations. First, generalizability is compromised due to our sample of young adultspredominantly White (83\%)-enrolled at a large Midwestern university. While the racial/ethnic breakdown of our sample mirrors that of the university, our sample is less diverse than that of the U.S. population generally [41]. Studies have shown higher rates of dating violence among African American compared to White adolescents $[1,8]$. Our dating violence prevalence results from a predominantly White sample may therefore be conservative. Second, males in our sample were under-represented. Third, with a response rate of $46.7 \%$, it is possible that respondents differed from non-respondents in meaningful ways. Unfortunately, we did not have information on non-responders; therefore an assessment of response bias was not possible. It is not possible to determine whether those who responded to the survey were more or less likely to have a history of teen dating violence compared to non-responders. However, in our study of adults where we had limited data on nonrespondents, we performed a propensity score analysis to estimate the probability that a woman responded to the survey, based on age, length of enrollment in the health plan, and health care utilization in the year prior to the survey [29]. This analysis showed that the estimated probability of survey participation did not differ for women exposed to intimate partner violence compared to women who reported no intimate partner violence (estimated probability 0.58 vs. 0.57 respectively). Fourth, although retrospective dating violence assessment is the field's standard for assessing dating violence, it is possible that subjects did not accurately recall dating violence they experienced. We attempted to minimize recall bias by using a query method similar the timeline follow-back interview [22-24], which included starting with recent events and working back and which included memory prompts to facilitate subjects' recall. Even with this detailed assessment approach, it is possible that subjects mis-estimated dating violence they experienced [25].

\section{Conclusions}

We used a query approach similar to the timeline follow-back interview method to facilitate recall of dating violence victimization experiences in a sample of males and females. Our study documented dating violence victimization experiences across the teen years, from age 13 to 19 , including dating violence types, frequency, number of abusive partners, and age at first occurrence-providing important information for health professionals and others to respond to a very common problem among teens, even those at higher socioeconomic levels who go on to college. Our results point to the need to amplify primary and secondary prevention efforts; school-based programs have been effective in reducing dating violence occurrence in adolescents $[1,21,42-49]$. As well, with females experiencing sexual pressure at high rates and by multiple partners, there must be a concerted effort to discuss sexual health, including healthy relationships, healthy sexual boundaries, and consent; health care settings offer a safe, confidential place for such conversations.

\section{Competing interests}

The authors declare they have no competing financial or non-financial interests.

\section{Authors' contributions}

AEB conceptualized the study and survey, oversaw data collection and analysis, and wrote the manuscript with co-authors' input. MA helped design the survey, conducted the data analysis and critically reviewed the manuscript. JMN helped conceptualize the study and survey, added to the statistical analysis, and critically reviewed the manuscript. $\mathrm{SBH}, \mathrm{CB}$, and DS helped conceptualize the study and survey, and critically reviewed the manuscript. All authors read and approved the final manuscript.

\section{Author details}

'Human Development and Family Science, The Ohio State University, Columbus, OH, USA. ${ }^{2}$ Center for Injury Research and Policy, Nationwide Children's Hospital, Columbus, OH, USA. ${ }^{3}$ Group Health Research Institute, Seattle, WA, USA. ${ }^{4}$ College of Public Health, The Ohio State University, Columbus, OH, USA. ${ }^{5}$ Student Wellness Center, The Ohio State University, Columbus, $\mathrm{OH}$, USA. 
Received: 8 March 2012 Accepted: 27 July 2012

Published: 10 August 2012

\section{References}

1. Foshee VA, Linder GF, Bauman KE, et al: The Safe Dates Project: Theoretical basis, evaluation design, and selected baseline findings. American Journal of Preventive Medicine 1996, 12:39-47.

2. Ackard DM, Eisenberg ME, Neumark-Sztainer D: Long-term impact of adolescent dating violence on the behavioral and psychological health of male and female youth. J Pediatr 2007, 151(5):476-481.

3. Ackard DM, Neumark-Sztainer D: Date violence and date rape among adolescents: Associations with disordered eating behaviors and psychological health. Child Abuse \& Neglect 2002, 26:455-473.

4. Coker AL, McKeown RE, Sanderson M, et al: Severe dating violence and quality of life among South Carolina high school students. Am J of Prev Med 2000, 19:220-227.

5. Olshen E, McVeigh KH, Wunsch-Hitzig RA, et al: Dating violence, sexual assault, and suicide attempts among urban teenagers. Archives of Pediatrics and Adolescent Medicine 2007, 161(6):539-545.

6. Silverman JG, Raj A, Mucci LA, et al: Dating violence against adolescent girls and associated substance use, unhealthy weight control, sexual risk behavior, pregnancy, and suicidality. JAMA 2001, 286:572-579.

7. Swahn MH, Simon TR, Arias I, et al: Measuring sex differences in violence victimization and perpetration within date and same-sex peer relationships. Journal of Interpersonal Violence 2008, 23:1120-1138.

8. Centers for Disease Control and Prevention: Physical dating violence among high school students - United States, 2003. MMWR 2006, 55(19):532-535.

9. Swahn MH, Simon TR, Hertz MF, et al: Linking dating violence, peer violence, and suicidal behaviors among high-risk youth. American Journal of Preventive Medicine 2008, 34(1):30-38.

10. Temple JR, Freeman DH Jr: Dating violence and substance abuse among ethnically diverse adolescents. Journal of Interpersonal Violence 2011, 26(4):701-718.

11. Yan FA, Howard DE, Beck KH, et al: Psychosocial correlates of physical dating violence victimization among Latino early adolescents. Journal of Interpersonal Violence 2010, 25(5):808-831. 2010.

12. Halpern $C T$, Young ML, Waller MW, et al: Prevalence of partner violence in same sex romantic and sexual relationships in a nationally representative sample. J Adolesc Health 2004, 35(2):124-131.

13. Swahn MH, Alemdar M, Whitaker DJ: Nonreciprocal and reciprocal dating violence and injury occurrence among urban youth. Western Journal of Emergency Medicine 2010, 11(3):264-268.

14. Smith PH, White JW, Holland $\mathrm{L}$ : A longitudinal perspective on dating violence among adolescent and college-age women. Am J Public Health 2003, 93:1104-1109.

15. Halpern $C T$, Spriggs AL, Martin SL, et al: Patterns of intimate partner violence victimization form adolescence to young adulthood in a nationally representative sample. J Adolesc Health 2009, 45(5):508-518.

16. GidyCz CA, Orchowski LM, King CR, et al: Sexual victimization and health risk behaviors: a prospective analysis of college women. Journal of Interpersonal Violence 2008, 23(6):744-763.

17. Himelein MJ: Risk factors for sexual victimization in dating: a longitudinal study of college women. Psychol Women Q 1995, 19(1):31-48.

18. Rich CL, Gidycz CA, Warkentin JB, et al: Child and adolescent abuse and subsequent victimization: a prospective study. Child Abuse and Neglect 2005, 29(12):1373-1394.

19. Humphrey JA, White JW: Women's vulnerability to sexual assault from adolescence to adulthood. J Adolesc Heal 2000, 27(6):419-424.

20. Spriggs AL, Halpern CT, Martin SL: Continuity of adolescent and early adult partner violence victimization: association with witnessing violent crime in adolescence. Journal of Epidemiology and Community Health 2009, 63(9):741-748.

21. Foshee VA, Bauman KE, Ennett ST, et al: Assessing the long-term effects of the Safe Dates program and a booster in preventing and reducing adolescent dating violence victimization and perpetration. Am J Public Health 2004, 94:619-624.

22. Tanney MR, Naar-King S, Murphy DA, et al: Multiple risk behaviors among youth living with human immunodeficiency virus in five U.S. cities. $J$ Adolesc Health 2010, 46(1):11-16.
23. Evans SM, Levin FR, Brooks DJ, et al: A pilot double-blind treatment trial of memantine for alcohol dependence. Alcohol Clin Exp Res 2007, 31(5):775-782

24. Sacks JA, Drake RE, Williams VF, et al: Utility of the time-line follow-back to assess substance use among homeless adolescents. Journal of Nervous and Mental Disorders 2003, 191(3):145-153

25. Widom CS, DuMont K, Czaja SJ: A prospective investigation of major depressive disorder and comorbidity in abused and neglected children grown up. Arch Gen Psychiatry 2007, 64(1):49-56.

26. Committee on the Prevention of Mental Disorders and Substance Abuse Among Children. Preventing Mental: Emotional and Behavioral Disorders Among Young People: Progress and Possibilities. Washington, D. C: National Research Council and Institute of Medicine; 2009.

27. Richards J, Wiese C, Katon W, et al: Surveying adolescents enrolled in a regional health care delivery organization: mail and phone followup-what works and at what cost? J Am Board Fam Med 2010, 23(4):534-541.

28. Fowler FJJ, Gallagher PM, Stringfellow VL, et al: Using telephone interviews to reduce nonresponse bias to mail surveys of health plan members. Medical Care 2002, 40(3):190-200.

29. Thompson RS, Bonomi AE, Anderson M, et al: Intimate partner violence: Prevalence, types, and chronicity in adult women. Am J Prev Med 2006, 30:447-457.

30. Bonomi AE, Anderson ML, Cannon EA, et al: Prevalence and health associated with intimate partner violence in insured Hispanic and non-Hispanic women. Am J Prev Med 2009, 36(1):43-48.

31. Bonomi AE, Anderson ML, Reid RJ, et al: Medical and psychosocial diagnoses in women with a history of intimate partner violence. Archives of Internal Medicine 2009, 169(18):1692-1697.

32. Bonomi AE, Anderson ML, Rivara FP, et al: Health outcomes in women with physical and/or sexual intimate partner violence exposure. J Women's Health 2007, 16(7):987-97.

33. Bonomi AE, Anderson ML, Rivara FP, et al: Health care utilization and costs associated with physical and non-physical intimate partner violence. Heal Serv Res 2009, 44(3):1052-1067.

34. Bonomi $\mathrm{AE}$, Thompson $\mathrm{RS}$, Anderson $\mathrm{ML}$, et al: Intimate partner violence and women's physical, mental, and social functioning. Am J Prev Med 2006, 30:458-466.

35. Rivara FP, Anderson ML, Fishman P, et al: Healthcare utilization and costs for women with a history of intimate partner violence. Am J Prev Med 2007, 32(2):89-96.

36. Rivara FP, Anderson ML, Fishman PA, et al: Time period cohort effects of intimate partner violence. Violence and Victims 2009, 24(5):627-638.

37. Rivara FP, Anderson ML, Fishman P, et al: Intimate partner violence and health care costs and utilization for children living in the home. Pediatrics 2007, 120(6):1270-1277.

38. Reid RJ, Bonomi AE, Rivara FP, et al: Intimate partner violence among men prevalence, chronicity, and health effects. Am J Prev Med 2008, 34(6):478-485.

39. Hickman $L$, Jaycox LH, Aronoff J: Dating violence among adolescents: Prevalence, gender distribution, and prevention program effectiveness. Trauma, Violence \& Abuse 2004, 5:123-142.

40. Centers for Disease Control and Prevention: Youth Risk Behavior Surveillance - United States, 2009. MMWR 2010, 59(SS-5):1-142

41. U.S. Census Bureau. American Community Survey, 2005. [cited 2007 June 26]; Available from: http://factfinder.census.gov/servlet/ ADPGeoSearchByListServlet?ds_name=ACS_2005_EST_G00_\&_lang= en\&_ts $=197804625156$

42. Foshee VA, Bauman KE, Greene WF, et al: The Safe Dates program: 1-year follow-up results. Am J Public Health 2000, 90:1619-1622.

43. Jaffe $P G$, Sudermann M, Reitzel D, et al: An evaluation of a secondary school primary prevention program on violence in intimate relationships. Violence \& Victims 1992, 7:129-146.

44. Foshee VA, Bauman KE, Arriaga XB, et al: An evaluation of Safe Dates, an adolescent dating violence prevention program. Am J Public Health 1998 , 88:45-50.

45. Lavoie F, Vezina L, Piche $C$, et al: Evaluation of a prevention program for violence in teen dating relationships. Journal of Interpersonal Violence 1995, 10:516-524. 
46. Avery-Leaf $\mathrm{S}$, Cascardi M, O'Leary KD, et al: Efficacy of a dating violence prevention program on attitudes justifying aggression. J Adolesc Health 1997, 21:11-17.

47. Macgowan MJ: An evaluation of a dating violence prevention program for middle school students. Violence \& Victims 1997, 12:223-235.

48. Krajewski SS, Rybarik MF, Dosch MF, et al: Results of a curriculum intervention with seventh graders regarding violence in relationships. Journal of Family Violence 1996, 11:93-112.

49. Weisz AN, Black BM: Evaluating a sexual assault and dating violence prevention program for urban youths. Soc Work Res 2001, 25:89-100.

doi:10.1186/1471-2458-12-637

Cite this article as: Bonomi et al:: Dating violence victimization across the teen years: Abuse frequency, number of abusive partners, and age at first occurrence. BMC Public Health 2012 12:637.

\section{Submit your next manuscript to BioMed Central and take full advantage of:}

- Convenient online submission

- Thorough peer review

- No space constraints or color figure charges

- Immediate publication on acceptance

- Inclusion in PubMed, CAS, Scopus and Google Scholar

- Research which is freely available for redistribution 